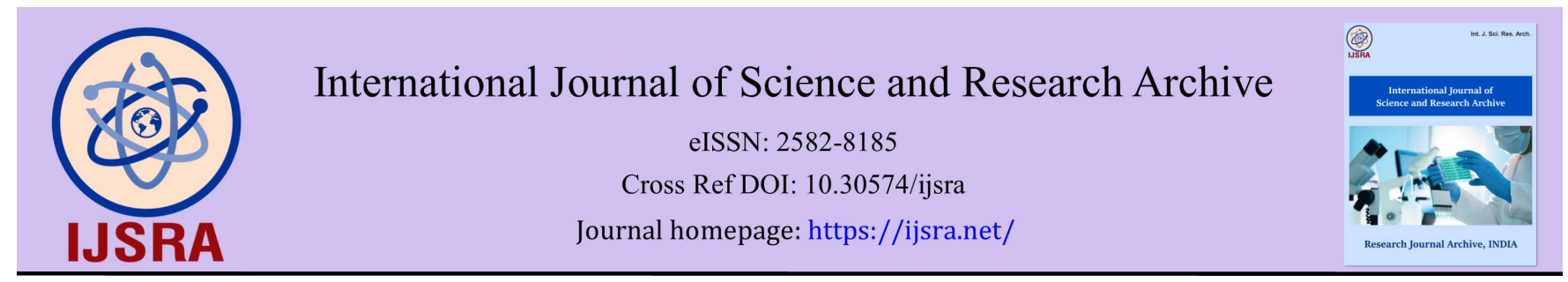

(RESEARCH ARTICLE)

\title{
Music - A double edged sword for students in COVID scenario
}

\author{
Kiran Naik*, Ravi KS and Pragati \\ ENT \& HNS, Adichunchanagiri Institute of Medical Sciences \& Research Institute, B.G. Nagar, Nagamangala, Mandya, \\ Karnataka, India.
}

International Journal of Science and Research Archive, 2021, 03(01), 005-008

Publication history: Received on 24 May 2021; revised on 04 July 2021; accepted on 08 July 2021

Article DOI: https://doi.org/10.30574/ijsra.2021.3.1.0089

\begin{abstract}
Background: Hearing loss is often thought of as a natural phenomenon of the aging process. However younger people with repeated usage of ear phone music are reporting nowadays with hearing impairment and more during this COVID pandemic era. In today's society, these devices are indispensable and are part of day-to-day life and because of the restriction on outdoor movement in COVID pandemic more and more people are reliant on ear phone music to allay boredom. Hence, this study was conducted to create awareness regarding prolonged exposure to loud noise either through an MP3 player or cell phone music.
\end{abstract}

Materials and Methods: A prospective study was done compromising 400 students from Shri Adichunchanagiri Institute of Medical Sciences from March 2020 to December 2020. They were divided into four groups using a questionnaire, Group A comprising 100 students who had a habit of listening to music through ear phones at least $2 \mathrm{~h}$ a day, Group B comprising 100 students who are used to earphone music less than $1 \mathrm{~h}$ per day and Group C comprising of 100 students who very occasionally use ear phones, but hear music mostly through speakers and Group D comprising of 100 students who are not used to ear phone music. All the 400 students studied were attending online classes as per the college schedule which constituted 3-4 hours daily. All the groups were subjected to pure tone audiometry when they reported back to their regular offline classes as the pandemic reduced in January 2021 and the audiogram obtained.

Results and Observations: The study revealed high frequency hearing loss in 6\% of Group A and 2\% in Group B; whereas, in there were no hearing impairment in Groups C and D indicating a significant role of prolonged ear phone music as a cause of high frequency hearing loss in students. The thin percentage and absence of hearing loss in Groups $B, C$, and D suggests the impact of the duration of exposure also has a role in the pathology.

Conclusion: This study proves beyond doubt that the prolonged usage of loud ear phone music is harmful to the ears and also the COVID induced movement restriction precipitated the indiscriminate use of ear phone music which further increased the causation.

Keywords: Ear phone music; prolonged usage; High frequency hearing loss; COVID pandemic era

\section{Introduction}

Hearing loss is often thought of as a natural phenomenon of the aging process. However, studies are beginning to show that hearing loss is becoming increasingly more common amongst younger people. Approximately, 20-30 million people between the ages of 20 and 69 years have high frequency hearing loss due to chronic exposure to loud noise above 90 decibels $(\mathrm{dB})$ of MP3 players and cellphones, according to the National Institute of Deafness [1]. If you are one of the

\footnotetext{
${ }^{*}$ Corresponding author: Kiran Naik

ENT \& HNS, Adichunchanagiri Institute of Medical Sciences \& Research Institute, B.G. Nagar, Nagamangala, Mandya, Karnataka, India.

Copyright $(2021$ Author(s) retain the copyright of this article. This article is published under the terms of the Creative Commons Attribution Liscense 4.0.
} 
millions who enjoy listening to a MP3 player or cellphone music to allay boredom or to pass time, then you might be at risk for hearing loss from headphones or earphones. This factor is accentuated by the present COVID scenario which has forced students to be confined to homes. So students are using their leisure time to listen to music using ear phones which has become a favourite pass time for students which ranges from hours. So COVID confinement has increased the duration of exposure to ear phone music by more than 2-3 hours than the pre COVID days. Studies have shown that most MP3 players today can produce sounds up to $120 \mathrm{~dB}$ and that long-term cell phone use to hear music may cause damage in the inner ear. In today's society, these devices are indispensable and are part of day-to-day life [2]. Hence, this study was conducted to create awareness regarding prolonged exposure to loud noise either through an MP3 player or cell phone music and also to unmask one more complication of COVID pandemic.

\section{Material and methods}

A total of 400 students from Shri Adichunchanagiri Institute of Medical Sciences were chosen as part of the study from March 2020 to December 2020. Due to COVID pandemic these students were confined to their homes for almost 10 months. As per the syllabus they were undergoing online classes. But these students were using music in their spare time like any other adolescent. So a study was devised to analyze whether this usage of music was causing any hearing disorders in them. Initially, a questionnaire was set up and given to all the students of all the 400 students. The questionnaire was regarding the usage of ear phone music and the duration of usage per day. Based upon the answers from the questionnaire, 400 students were chosen as a part of the study and were divided into four groups, Group A comprising 100 students who had a habit of listening to music through ear phones at least $2 \mathrm{~h}$ a day, Group B comprising 100 students who are used to earphone music less than $1 \mathrm{~h}$ per day and Group C comprising of 100 students who very occasionally use ear phones, but hear music mostly through speakers and Group D comprising of 100 students who are usually not using earphones for music. The persons who had a history of decreased hearing from any other cause like discharging ears or trauma were excluded from the study. Informed consent was taken from all the 400 students about the nature of the study and the investigation they were to undergo. All the groups were subjected to pure tone audiometry at the Ear, Nose, and Throat (ENT) and Head and Neck Surgery (HNS) Department of Adichunchanagiri Medical College when they came back to the college in January 2021 and the audiogram obtained. Group A \& B persons were advised to refrain from further use of ear phone music after the first audiometry. Repeat audiometry was done for all the four groups after a period of 3 months in March 2021 and the results noted.

\section{Observations and Results}

The age and sex percentages of the 400 students are tabled below [Tables 1].

Table 1 Age \& sex percentages of the 400 students

\begin{tabular}{|c|c|c|}
\hline Age & Male & Female \\
\hline $18-20$ & $124(31 \%)$ & $168(42 \%)$ \\
\hline $21-23$ & $44(11 \%)$ & $64(16 \%)$ \\
\hline Total & $168(42 \%)$ & $232(58 \%)$ \\
\hline
\end{tabular}

Pure tone audiometry of all the students revealed that 6\% (6 students) of Group A had high frequency sensorineural hearing loss (2 students had a hearing loss of 10-20 dB and 4 students had a loss of 20-30 dB). Group B showed high frequency hearing loss in 2\% (2 students, that is, 1 having loss of 10-20 dB and 1having 20-30 dB).

Table 2 Pure tone audiometry findings in the 400 students- first time

\begin{tabular}{|l|c|c|}
\hline Group & High frequency hearing loss- 10-20 db & High frequency hearing loss- 20-30 db \\
\hline Group A & 2 & 4 \\
\hline Group B & 1 & 1 \\
\hline Group C & 0 & 0 \\
\hline Group D & 0 & 0 \\
\hline
\end{tabular}


Groups C and D showed no abnormal changes in audiometry. After 3 months the repeat audiometry results showed a drastic decrease in the number of students showing hearing loss. Group A had a significant reduction in the positive result, that is, out of 6 students who had high frequency hearing loss in Group A, the repeat audiometry revealed only 1 to be persisting within the loss that too of only 10-20 db. So, there was a substantial decrease in the number and the amount of hearing loss after the period of abstinence from ear phone music. Also, Group B who had 2 students suffering from hearing loss in the first instance showed only 1 student persisting with the loss after 3 months that too in the 10$20 \mathrm{~dB}$ category. This study clearly reveals the harmful effects of prolonged ear phone music usage by showing the significant number of persons having high frequency hearing loss. Also, this study stresses that the changes occurred are temporary and are reversible if intervened at the right time by demonstrating the decrease in the number of positive cases after 3 months of abstinence from ear phone music.

Table 3 Pure tone audiometry findings in the 400 students- after 3 months of stoppage of ear phone music usage

\begin{tabular}{|l|c|c|}
\hline Group & High frequency hearing loss- 10-20 db & High frequency hearing loss- 20-30 db \\
\hline Group A & 1 & 0 \\
\hline Group B & 1 & 0 \\
\hline Group C & 0 & 0 \\
\hline Group D & 0 & 0 \\
\hline
\end{tabular}

\section{Discussion}

The more common and easily available cell phone music has become one of the most common devices for listening to music for both adults and teens. It is a very common practice among students to put on their ear phone and listen to music whenever they get time and also the ease of availability of music in all the cell phones has made the usage more rampant. This usage is increased due to the confinement of the students to indoors due to the prevailing COVID pandemic. Also due to the lack of other forms of entertainment in COVID scenario, most of the students resort to only usage of ear phones for music, games. The private and continual blaring of music through ear buds is seductive to so many because it creates a personal buffer that drowns out the outside world and relieves stress by bringing beats so close one can feel the vibrations. This intense, intimate merger with music, however, can be fatal to hair cells in the ears and lead to hearing loss. The risk is most prevalent among teens, according to Colorado University audiologists whose research determined that not only do teens blast music louder than the average adult but that they are mostly oblivious to how excessive their volume is [3].

Researchers warn however that just 5 min of listening at the highest volume on a daily basis is enough to erode hearing over time. Once hair cells are killed by hearing loss and music use, they will skew the sound signals being sent from the ears to the brain. At that point, the brain may not be able to decipher sounds at normal pitches. Some listeners can suffer loss after one time exposure to loud music in a concert, particularly if they have sat close to speakers. Generally, such individuals will notice tinnitus, or ear ringing, the day after; such ringing is a warning sign. Usually this is not the case in cell phone music usage, the changes that occur are gradual and the warning signs like tinnitus are less and so the usual findings of hearing loss are detected late. Also, the losses from infrequent exposure to loud music are mostly temporary; whereas, in prolonged usage of MP3 or cell phone music the changes that occur are usually long standing unlike this study.

This study creates awareness about the correct usage of pandemic forced home time and stresses the importance of awareness regarding prolonged usage of ear phone music by demonstrating the significant number of persons affected by ear phone music and also the remission in the findings following abstinence from usage of ear phone music. Restricting the maximum output level of personal music players to $90 \mathrm{~dB}$ would therefore limit the risk of hearing loss [4]. Even though most of the students are aware of the fact that loud noise is dangerous to the ears, they tend to underestimate the significance of the exposure through a MP3 player or a cell phone music usage. A plausible explanation for this underestimation might lie in the gradual development of hearing loss and because most people with mild high frequency hearing loss are unaware of their impairment. Indeed, participants who had experienced tinnitus did not consider this as a warning that their hearing was susceptible to damage from loud music, because the tinnitus later disappeared without leaving any noticeable damage. Furthermore, adolescents showed no true understanding of how to determine which volume was too loud; although volumes near $90 \mathrm{~dB}$ are assumed to be dangerous, only those of approximately 120-140 dB are experienced as unpleasant and painful. The danger of hearing loss is thus easily underestimated. Hence, the student population needs awareness regarding such practices which can be attained by 
conducting classes and stressing about the harmful nature of prolonged usage of ear phone music. COVID has taught a lot of lessons to mankind and this study unravels one more lesson to understand to modify our lifestyle.

\section{Conclusion}

This study creates awareness about the correct usage of pandemic forced home time and stresses the importance of awareness regarding prolonged usage of ear phone music and its effects on hearing.

\section{Compliance with ethical standards}

\section{Acknowledgments}

I would like to acknowledge the services of our audiologist Ms. Chaitra in carrying out this study.

Disclosure of conflict of interest

There is no conflict of interest among the authors with respect to the study.

\section{Statement of informed consent}

Informed consent was obtained from all individual participants included in the study.

\section{References}

[1] Zhao F, Manchaiah VK, French D, Price SM. Music exposure and hearing disorders: An overview. Int J Audiol 2010; 49: 54-64.

[2] Hodgetts WE, Rieger JM, Szarko RA. The effects of listening environment and earphone style on preferred listening levels of normal hearing adults using an MP3 player. Ear Hear. 2007; 28: 290-7.

[3] Henry P, Foots A. Comparison of user volume control settings for portable music players with three earphone configurations in quiet and noisy environments. J Am Acad Audiol. 2012; 23:182-91.

[4] Quintanilla-Dieck Mde L, Artunduaga MA, Eavey RD. Intentional exposure to loud music: The second MTV.com survey reveals an opportunity to educate. J Pediatr. 2009; 155: 550-5. 